\title{
Parosmia and hyposmia induced by solvent exposure
}

\author{
EDWARD A. EMMETT \\ Department of Environmental Health, University of Cincinnati, Ohio, USA
}

An intact sense of smell contributes to our appreciation of many of the better qualities of life. Loss or perversion of this sense may thus be a source of annoyance to any worker. In certain occupations olfactory damage may prove disastrous, as in the development of anosmia in a vintner or fragrance tester or in one who relies upon smell to detect noxious or lethal vapours or gases. Little attention has been given in the English language medical literature to occupationally-induced disorders of olfaction. For this reason a case of hyposmia and parosmia associated with exposure to certain solvents is described and a brief review made of other occupational exposures described as leading to a loss or distortion of smell.

\section{Report of a case}

In March 1974 a 41-year-old pipefitter complained of a change in his powers of smell. Over 10 weeks he had noticed the gradual onset of a constant unpleasant smell, described as between that of acetone and hydrofuran, solvents used in his work. This odour was intensified by a variety of unrelated fragrances such as aftershave lotions, perfumes, cola drinks, and many foods. The odour was worse at night and would occasionally wake him. Other family members could not smell anything at times when he was complaining of an unusual odour. In addition he felt his sense of smell to be diminished so that foods such as meats had lost their characteristic taste. He smoked one packet of cigarettes a day but noted no marked change in the taste of tobacco. He felt generally well apart from some vague tiredness and occasional dull morning headaches relieved by aspirin.

The patient had slight rhinorrhea when he worked with solvents but no conjunctival irritation, cough, phlegm, or nausea. After reducing his work exposure to solvents the constant smell decreased but the altered taste remained. His family physician prescribed oral diphenhydramine without symptomatic improvement.

For three months he had been working for about $40 \%$ of the time fitting polyvinyl chloride piping. Pipe lengths were cleaned and prepared for union with acetone or a mixture of tetrahydrofuran and cyclohexanone. A glue containing tetrahydrofuran as solvent was applied before welding with a torch; rarely a polyvinyl chloride rod was also used in the welding process. The pipe-fitting was usually performed in confined unventilated ceilings at an ambient temperature of $8^{\circ} \mathrm{C}$, although pipefitting was occasionally done in hot areas. Respirators were not generally used. The solvent odours were very strong under these conditions. Thin gloves which were not impervious to the solvent were sometimes used. After contact he washed his hands, but seldom at intervals of less than two hours. He had a shower every evening on return from work. A pipefitter's assistant who worked with him, but in less proximity to the fitting operations, reported no symptoms.

The patient had enjoyed good health apart from the removal of a pilonidal cyst 17 years previously. He took occasional aspirin, but no other drugs, drank in moderation, and did not use nasal drops or sprays. There was no history of recent upper respiratory tract infection. Before the onset of this problem he had had very sensitive smell and had previously been selected from a number of employees to detect gas leak odours.

On examination, he appeared healthy, well nourished, and was normotensive. He could taste salt and sugar normally. He reacted to the irritant effect of ammonia. On olfactory testing he was able to identify a standard cinnamon preparation with either nostril and could detect but not identify an odour stimulus from standard aldehydes, aromatic oils, and ester fragrances. He was unable to detect standard solutions of oil of bergamot or essence of peppermint through either nostril. His responses were reproducible on this and other occasions and there was no reason to suspect any fabrication. Results of olfactory testing on various occasions are given in the Table.

There was marginal injection of the nasal mucosa, but nasal conchae and septum appeared normal. Pupil reactions, fundoscopy, visual fields, cranial nerves, and extrapyramidal motor, sensory and reflex examination were normal. Physical examination was otherwise normal.

Radiography of the skull and paranasal sinuses were normal apart from slight asymmetry in the aeration of 
the maxillary antra, possibly because of mucosal thickening. Haemoglobin, white cell and differential counts, serum calcium, inorganic phosphate, glucose, blood urea nitrogen, uric acid, cholesterol, total bilirubin, alkaline phosphatase and glutamic oxaloacetic transferase were within normal limits. The serum lactic dehydrogenase was marginally raised at $210 \mathrm{mU} / \mathrm{ml}$ (normal 90-200 $\mathrm{mU} / \mathrm{ml}$ ), six weeks later it was within normal limits at $185 \mathrm{mU} / \mathrm{ml}$.

A provisional diagnosis was made of hyposmia and parosmia associated with solvent exposure. From this time onwards he had no significant exposure to any of these solvents (tetrahydrofuran, cyclohexanone, or acetone).

During the ensuing four weeks the constant odour became less marked and changed in character, although parageusia had become particularly unpleasant. Two weeks later the persistent odour had virtually vanished and the patient felt he could detect differences between certain smells, for example between shaving cream and exhaust fumes or petrol. However, meat and coffee were beginning to taste particularly unpleasant. A feeling of vague tiredness persisted. Detailed examination remained unchanged apart from slight change in olfactory sensation as the patient could now detect the odour of oil of bergamot (Table).

\section{TABLE}

Results of Repeated Tests of Ability to Identify Selected Fragrance Materials (March to NOVEMBER 1974)

\begin{tabular}{|c|c|c|c|c|}
\hline Smell & March & May & August & $\begin{array}{l}\text { Nov- } \\
\text { ember }\end{array}$ \\
\hline $\begin{array}{l}\text { Cinnamon oil } \\
\text { Aldehyde fragrance } \\
\text { Aromatic oil fragrance } \\
\text { Ester fragrance . . } \\
\text { Essence of peppermint } \\
\text { Oil of bergamot .. } \\
\text { Hydroxycitronellal } \\
\text { solution }\end{array}$ & $\begin{array}{l}\text { I } \\
\text { D } \\
\text { D } \\
\text { D } \\
\text { U } \\
\text { U } \\
\text { NT }\end{array}$ & $\begin{array}{l}\text { I } \\
\text { D } \\
\text { D } \\
\text { D } \\
\text { D } \\
\text { U } \\
\text { NT }\end{array}$ & $\begin{array}{l}\text { I } \\
\text { NT } \\
\text { D } \\
\text { D } \\
\text { D } \\
\text { D } \\
\text { NT }\end{array}$ & $\begin{array}{l}\text { I } \\
\text { NT } \\
\text { D } \\
\text { D } \\
\text { D } \\
\text { D } \\
\text { U }\end{array}$ \\
\hline
\end{tabular}

I = Identify

$\mathrm{D}=$ Detect but not identify

$\mathrm{U}=$ Unable to detect

$\mathrm{NT}=$ Not tested

Seven months after he had initially presented, his symptoms were little changed. His threshold of smell remained increased, and unlike other employees he was able to repair a broken sewer without discomfort. A number of foods including fried food, greasy or fatty meats, and certain soft drinks still elicited a strange and unpleasant taste. Fragrances, for example in toiletries and certain fumes continued to evoke an unpleasantsensation. Olfactory examination was essentially unchanged as shown in the Table.

\section{Discussion}

A review of the literature shows that the features which characterized this patient's complaints are characteristic of parosmia and hyposmia induced by industrial chemicals.

In this case there was an evident temporal relationship with the solvent exposure, as the symptoms progressed while the exposure continued and slowly improved after exposure had stopped. The initial persistent unpleasant odour was similar to the odour provoked by the solvents to which he was exposed. Blind testing of smell on different occasions with a large variety of volatile oils and other materials revealed consistent and reproducible responses with evidence of slight progressive recovery during the ensuing nine months. The loss of sensation was confined to olfaction. There was no distortion of the basic sensations of taste or of appreciation of trigeminal irritants such as ammonia. Such a selective loss is diagnostic of peripheral olfactory nerve damage and is said to exclude a diagnosis of hysteria (DeJong, 1958). A loss of perceived tastes usually accompanies a loss of smell, as in this case, because the recognition of flavours is largely an olfactory function (Grinker and Sahs, 1966). The patient worked with several solvents, namely acetone, tetrahydrofuran, and cyclohexanone and we do not know which of these was responsible for his symptoms. Unfortunately quantitative environmental data are not available.

In adult man the olfactory receptors are located in the postero-superior parts of the nasal cavity and the opposite region of the wall of the superior conchae (Ottoson, 1963). The exposed position of the olfactory end-fibres probably accounts for their frequent involvement in local disease of the nose and their tendency to be damaged by inhaled chemicals (Grinker and Sahs, 1966). The unmyelinated olfactory axons, which are extraordinarily thin, retain their individuality as they pierce the lamina cribrosa and until they synapse in the olfactory bulb. Axons of the second order travel posteriorly in the olfactory tract to various parts of the forebrain, but some fibres cross in the anterior commissure to end in the opposite olfactory bulb (LeGros Clark, 1957; Gorman, 1964). Since there is bilateral innervation central to the decussation of the olfactory pathways, lesions of the olfactory cortex do not produce anosmia (DeJong, 1958). It should be emphasized that an appreciation of the presence of smell, even without identification, is sufficient to rule out anosmia (DeJong, 1958). Hallucinations of smell are sometimes seen in paranoid and toxic states, however, the sense of taste and recognition of flavours are usually unaffected (Grinker and Sahs, 1966). The actual biochemical mechanisms of olfactory sensation are essentially unknown (Ottoson, 1963).

Several industrial chemicals have been noted to produce hyposmia or anosmia with repeated exposures. These include hydrazine (Rossberg, 1965; 
Kittel, 1966; Rossberg, Schaupp, and Schmidt, 1966), carbon disulphide (Bedoni and Corbetta, 1958), benzol (Ferrari and Jemmi, 1966), oil of peppermint (Lenhardt and Rollin, 1969) and solvents used in paints (Rossberg et al., 1966). Hyposmia was noted in a medical assistant who repeatedly sniffed a jar of anginine tablets (Lenhardt and Rollin, 1969). A Russian study found that $30 \%$ of 216 shoe factory workers who used benzine, ethyl acetate, and butyl acetate had anosmia and others had greatly reduced olfaction compared with a control group (Dragomiretskii, 1970). Olfactory disorders which follow repeated chemical exposures have a relatively slow onset over months or years without either pronounced or persistent signs of mucous membrane irritation. The patient usually notices difficulty in identifying odoriferous materials although an indifferent sensation of odour may occur. Frequently unpleasant parosmia or cacosmia occurs on encountering any substance with a pronounced odour (Lenhardt and Rollin, 1969). The loss may be relatively permanent although some improvement may occur. The results of long-term follow-up are rarely available.

Anosmia or hyposmia may result from a single exposure to certain materials such as in a wine merchant who suffered permanent olfactory loss after sniffiing $6 \%$ sulphuric acid by mistake (Pfander, 1959). Similar injury has been described from hydrogen selenide (Symanski, 1950), phosphorus oxychloride (MacIntyre, 1971), and a pepper and cresol mixture (Lenhardt and Rollin, 1969). Hyposmia can also result from chronic irritation of the nasal mucous membranes by such nuisance dusts as chalk or potash (Lenhardt and Rollin, 1969) and iron carbonyl (Renninghoff, 1965). Certainly the number of materials described as causing olfactory disturbances is large, suggesting an analogy between the loss of smell in chemical workers and loss of hearing in workers exposed to noise.

Other chemicals are known to alter olfaction. Olfactory perception is temporarily diminished by formaldehyde in the inspired air which is the basis of its use in room and space deodorants (Gorman, 1964). Temporary hyposmia from formaldehyde is commonly noticed by pathologists. A number of therapeutic materials have been reported to cause anosmia including the local repeated use of vasoconstrictors or neomycin, and occasionally parenteral morphine, cocaine, antipyrine, and mercury or gold salts (Rebaltu, Lafon, and Calgfinger, 1972).

Parosmia may also follow a viral upper respiratory tract infection and may persist for many months although the ultimate prognosis is usually good (Grinker and Sahs, 1966). It may accompany head injury (Brain and Walton, 1969) especially with damage to the cribriform plate, tumours of the frontal lobe, olfactory bulb, tract or groove (Gorman
1964), or tabetic or senile atrophy of the olfactory system (Grinker and Sahs, 1966). There was no evidence for these causes or of local obstructive nasal disease in this patient.

\section{References}

Bedoni, C. and Corbetta, L. (1958). Le alterazioni dell' olfatto in alcune malattie professional: (solfocarbonismo, saturnismo, lavorazione delcromo). Annali di Laringologia, Otologia, Rinologia, e Faringologia, 57, 641-650.

Brain, R. L. and Walton, J. N. (1969). Brain's Diseases of the Nervous System, p. 142. Oxford University Press, London.

DeJong, R. N. (1958). The Neurologic Examination, 2nd edition. Hoeber, New York.

Dragomiretskii, V. D. (1970). The effect of small concentrations of solvents on the state of the mucous membrane of the upper respiratory tract. (In Russian). Zhurnal Ushnȳkh, Nosovȳkh i Gorlovȳkh Bolezneĭ, 30, 16-18.

Ferrari, C. and Jemmi, A. (1966). Rilievi clinici sulle funzioni cocleo-vestibolare ed olfattiva nei lavatori del benzola. Ateneo Parmensi, Sezione I: Acta BioMedica, 37, Suppl. 2, 207.

Gorman, W. (1964). The sense of smell. A clinical review. Eye, Ear, Nose and Throat, 43, 54-58.

Grinker, R. R. and Sahs, A. L. (1966). Neurology, 6th edition. Thomas, Springfield, Illinois.

Kittel, G. (1966). Discussion of Rossberg, G., Schaupp, H., and Schmidt, W. Z. Zeitschrift für Laryngologie, Rhinologie, Otologie und ihre Grenzgebiete, 45, 589.

LeGros Clark, W. E. (1957). Inquiries into anatomical basis of olfactory discrimination. Proceedings of the Royal Society, Series B. Biological Sciences, 146, 229.

Lenhardt, E. and Rollin, H. (1969). Berufsbedingte riechstörungen. H.N.O.-Wegweiser für die fachärztlich Praxis, 17, 104-106.

MacIntyre, I. (1971). Prolonged anosmia. British Medical Journal, 1, 709.

Ottoson, D. (1963). Some aspects of the function of the olfactory system. Pharmacological Reviews, 15, 1-42.

Pfander, F. (1959). Anosmie durch einmalignes einatmen von Schwefeldioxyd.H.N.O.-Wegweiser für die fachärztlich Praxis, 8, 59.

Rebaltu, J. P., Lafon, H., and Calgfinger, H. (1972). La pathologie iatrogéne en otorhino-laryngologie. Journal français d'Oto-Rhino-Laryngologie, Audio-Phonologie et Chirurgie Maxillo-Faciale, 21, 931-935.

Renninghoff, F. (1965). Geruchsstörung durch Metallstaub. H.N.O.-Wegweiser für die fachärztlich Praxis, 13,99.

Rossberg, G. (1965). Diskussion zu den Referaten und zu den Vortragen 1-3. Archiv für Ohren-, Nasen- und Kehlkopf heilkunde, 185, 503-504.

—, Schaupp, H., and Schmidt, W. (1966). Geruchsgeschmacksvermögen bei arbeitern der chemischen und Metallveranbeitenden Industrie. Zeitschrift für Laryngologie, Rhinologie, Otologie und ihre Grenzgebiete, 45, 571-590.

Symanski, H. (1950). Ein Fall von Wasserstoffvergiftung. Deutsche medizinische Wochenschrift, 75, 1730.

Received for publication 14 November 1975.

Accepted for publication 5 February 1976. 